\title{
LAPORAN KASUS: PERBANDINGAN PROSEDUR CUTLER BEARD DAN DIRECT CLORUSE PADA DEFEK PALPEBRA YANG LUAS AKIBAT TRAUMA DI RSU DR. SAIFUL ANWAR MALANG
}

\section{CASE REPORT: COMPARISON OF CUTLER BEARD PROCEDURE AND DIRECT CLORUSE FOR WIDE TRAUMATIC EYELID DEFECT IN SAIFUL ANWAR HOSPITAL MALANG}

\author{
M. Iwan Kurniawan, Elfina G Sadono \\ Laboratorium Ilmu Penyakit Mata Fakultas Kedokteran Universitas Brawijaya/RSU dr. Saiful Anwar Malang
}

\begin{abstract}
The paper aimed to report a different management of reconstruction for large traumatic upper eyelid defect. Case $1:$ a 17 years old woman with traumatic upper eyelid defect in the right eye since 2 years old. The defect was linear but wide, looks like a triangle defect. Defect had repaired by direct closure. After the operation the defect remain. Case $2:$ a 45 years old man with more than $50 \%$ traumatic upper eyelid defect in the left eye. Cutler-beard procedur was made to close the defect. Separation of the flap had been done at the second procedure. Cutler-beard procedure, done to the second patient, had succed to close the upper eyelid defect. Reconstruction procedure carried out for the first patient was not adequate to restore the large upper eyelid defect. Cutler-beard procedure is used for upper eyelid defect involving more than $50 \%$ seem to have a good result.
\end{abstract}

Key words : Cutler beard, Direct closure

\section{PENDAHULUAN}

Rekonstruksi palpebra adalah tindakan pembedahan yang bertujuan untuk memperbaiki palpebra seanatomis dan sefisiologis mungkin menjadi normal. Tujuan rekonstruksi yang ingin dicapai yaitu 1). mengembalikan fungsi palpebra secara adekuat; 2). mengembalikan fungsi palpebra sebagai pelindung dari bola mata; 3). memperhitungkan nilai estetika $(1,2,3)$.

Dalam rekonstruksi palpebra identifikasi anatomi merupakan keharusan. Pemahaman terhadap anatomi dua lapisan palpebra yaitu: lapisan anterior (kulit, otot orbikularis okuli) dan lapisan posterior (tarsus, konjungtiva palpebra, levator palpebra, otot muller) wajib diketahui $(1,2,3,4,5)$.

Kasus defek palpebra superior akibat trauma dengan luas lebih $50 \%$ perlu penanganan khusus. Metode Cutler Beard adalah melakukan penanaman sebagian palpebra superior untuk menutupi defek pada palpebra inferior. Keunggulan tehnik ini dibanding metode lainnya lebih sederhana dan dapat menutupi defek yang lebar. Tujuan laporan kasus ini menampilkan salah satu kasus menggunakan Cutler-Beard prosedur untuk menutup defek palpebra superior dibandingakan dengan tehnik lainnya.

Kasus 1

Seorang wanita umur 17 tahun mengalami trauma pada mata kanan, tertusuk bambu ketika berumur dua

Jurnal Kedokteran Brawijaya, Vol. XXIII, No. 3, Desember 2007 Korespondensi: Iwan Kurniawan; Lab. IImu Penyakit Mata FK Unibraw / RSU dr. Saiful Anwar Malang; JI. Jaksa Agung Suprapto No. 2; Telp. 0341 - 341945 tahun. Pasien mengeluh kelopak matanya tidak bisa menutup, pasien ingin dioperasi. Pemeriksaan visus mata kanan $1 / 300$, mata kiri $5 / 5$. Pada palpebra kanan terdapat defek lurus, berbentuk segitiga tumpul dengan lebar lebih $50 \%$. Levator action $10 \mathrm{~mm}$ dan terdapat lagoftalmus 2 $\mathrm{mm}$. Konjungtiva tidak didapatkan hiperemia sedangkan kornea didapatkan stafiloma dan neovaskularisasi. Pada pasien ini dilakukan penutupan langsung pada defek.

\section{Teknik operasi}

Prinsip operasi ini adalah menutup langsung defek palpebra superior dengan hanya melakukan pelebaran kulit. Dilakukan incisi untuk membuat luka baru pada tepi defek. Dieksplorasi lapisan posterior dan lapisan anterior palpebra, tampak konjungtiva \& tarsus. Dilakukan undermine luas pada kulit palpebra. Menggunakan benang vicryl 6.0 konjungtiva palpebra dijahit satu-satu selanjutnya tarsus dijahit juga menggunakan benang vicryl 6.0 satu-satu. Kulit palpebra dijahit dengan benang prolene 6.0 satu-satu. Selanjutnya dilakukan tarsoraphy $(1,3,6)$.

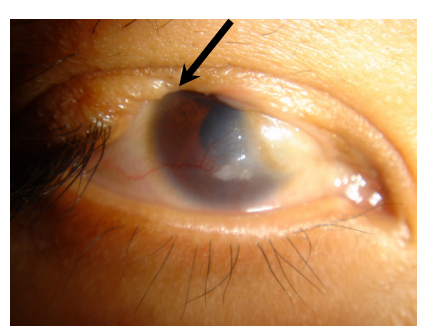

Gambar 1. Defek Palpebra Superior Kasus 1 


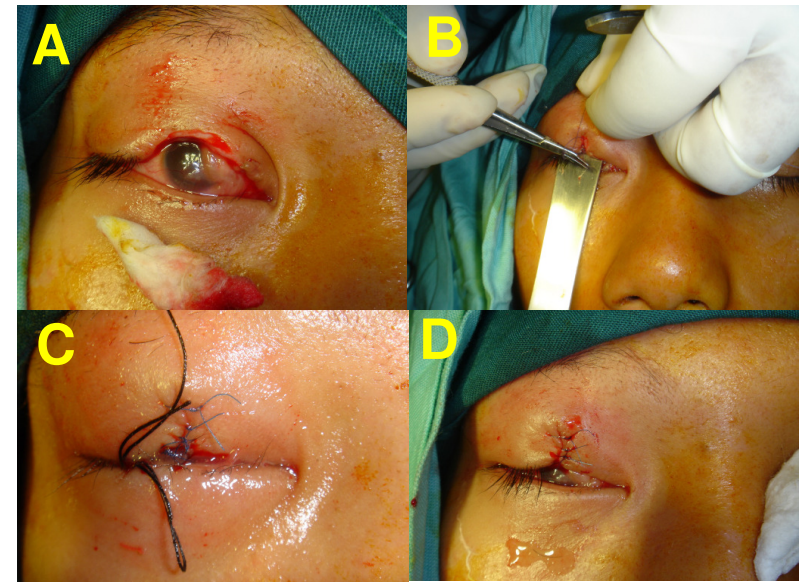

Gambar 2.Tehnik operasi jahitan langsung pada defek palpebra superior kasus $1, A$ : membuat luka baru, B: Konjungtiva dijahit dengan vicryl 6.0, C: kulit palpebra dijahit dengan prolene 6.0, D: tarsoraphy.

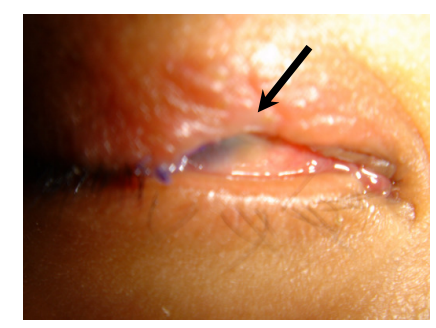

Gambar 3. Defek Masih Ada Setelah 2 Minggu Operasi

\section{Kasus 2}

Seorang laki-laki umur 42 tahun datang dengan keluhan kelopak mata kiri tidak dapat menutup setelah dijahit di salah satu rumah sakit setelah kecelakaan lalu lintas ketika jatuh dari motor. Pemeriksaan visus mata kanan 5/6,5 mata kiri 5/12. Mata kiri terdapat levator action $10 \mathrm{~mm}$ dan lagoftalmus $6 \mathrm{~mm}$. Defek palpebra lebih dari 50 $\%$ dan terdapat bekas jahitan. Dilakukan rekonstruksi palpebra dengan prosedur Cutler-Beard. Pada waktu explorasi didapatkan hilangnya lapisan anterior palpebra, tarsus dan konjungtiva robek dan terlipat oleh jahitan. Sehingga tidak perlu dilakukan graf kartilago dan mukosa bibir untuk menganti tarsus dan konjungtiva. Selanjutnya flap setelah 21 hari dipisahkan dengan anestesi umum.

\section{Teknik operasi}

Prinsip operasi ini adalah mengambil jaringan kulit di palpebra inferior untuk menutupi defek di palpebra superior. Dieksplorasi luka \& identifikasi lapisan palpebra. Konjungtiva palpebra dan tarsus robek dan terlipat oleh jahitan sebelumnya. Konjungtiva dijahit menggunakan benang vicryl 6.0. Incisi kulit palpebra dibuat defek baru berbentuk segi empat pada tepi luka. Dibuat marker garis horisontal sepanjang lebar luka di palpebra superior setinggi $4 \mathrm{~mm}$ dari margo palpebra inferior dan marker di sisi nasal dan temporal garis yang pertama kearah vertikal. Dibuat incisi sesuai garis yang telah dibuat sedalam kulit, selanjutnya kulit di undermine luas. Trial and error di lakukan, sampai kurang lebih kulit palpebra inferior yang advanced menutupi defek palpebra superior. Dilakukan incisi di tepi margo palpebra inferior sesuai dengan incisi sebelumnya. Kulit palpebra yang telah diadvanced dilewatkan ke celah palpebra inferior. Konjungtiva palpebra inferior dan superior dijahit dengan vicryl 6.0 secara delujur. Kemudian kulit palpebra superior dan inferior dijahit satusatu dengan prolene 6.0. Dengan incisi berbentuk segitiga, dog-ear yang terjadi dilateral dan nasal incisi margo palpebra inferior dijahit satu-satu dengan prolene 6.0.

Setelah 21 hari dengan anestesi umum, dilakukan pemisahan palpebra dengan memotong sesuai contour tepi palpebra superior menggunakan pisau dilanjutkan gunting bengkok Selanjutnya dijahit antara kulit palpebra dengan konjungtiva palpebra superior yang baru. Luka palpebra inferior di jahit kembali menggunakan benang prolene 6.0 secara subcutan.

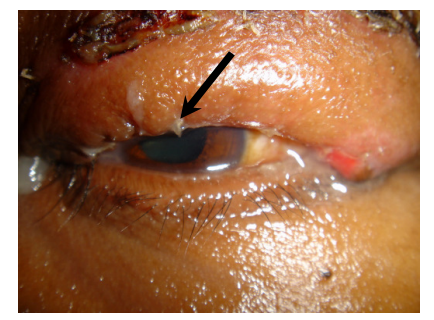

\section{Gambar 4. Defek Palpebra Superior pada Kasus 2}

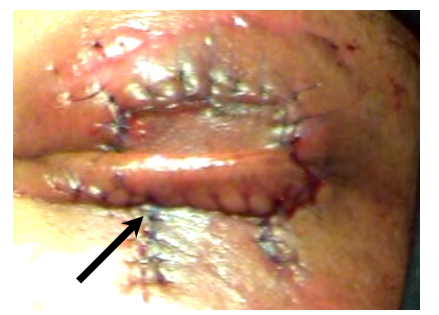

Gambar 5. Post Operasi dengan Flap dari Palpebra Inferior
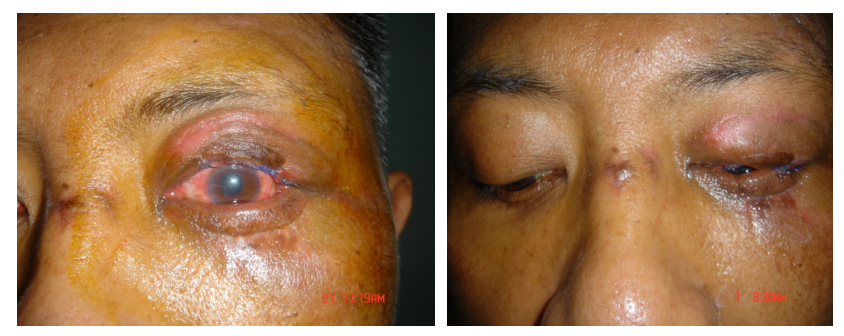

Gambar 6. Post Pemotongan Cuttler-Beard Flap/Bridge 


\section{DISKUSI}

Persiapan sebelum operasi merupakan tindakan yang sangat penting bagi pasien antara lain, penjelasan kepada pasien akan apa yang mungkin terjadi secara jujur dan jelas akan hasil dan akibat pembedahan yang akan dilakukan, dokumentasi perlu untuk mempertegas kondisi abnormal (1).

Ukuran defek pada palpebra sangat mempengaruhi tindakan tehnik yang akan dilakukan. Berikut ini patokan ukuran defek pada palpebra superior:

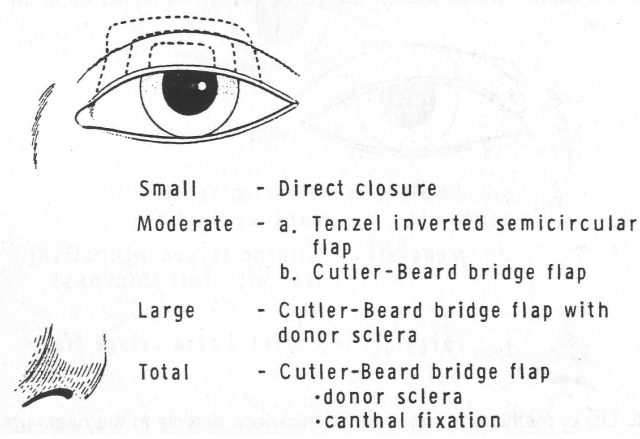

Gambar 6.Ukuran Defek dan Tindakan yang Bisa Digunakan. (Diambil dari: Clinton D.McCord, Jr . Oculoplastic Surgery, 1981; 213) (6)

Bashour (2005) membagi defek palpebra superior berdasar ukuran dan umur pasien (palpebra yang tight atau lax) sebagai berikut, untuk pasien muda (tight lids); kecil $25-35 \%$, sedang - 35-45\%, luas - lebih besar dari $55 \%$. Untuk pasien tua (lax lids); kecil - 35-45\%, sedang - 45$55 \%$,luas - lebih besar dari $65 \%$ (4). Jadi elastisitas dari kulit palpebra mempengaruhi tehnik operasi yang akan dilakukan (6).

Pada awalnya Cutler-Beard prosedur dipublikasikan sejak tahun 1955 digunakan untuk rekonstruksi palpebra superior sebagian atau total defek. Melebarkan flap palpebra inferior pars preseptal full thickness diantara flap bipedicle tepi palpebra inferior dan bagian pretarsal tersebut digunakan untuk menutupi defek palpebra superior. Prosedur selanjutnya setelah 6-8 minggu dipisahkan antara palpebra inferior tersebut sesuai garis tepi palpebra superior $(2,4,7,8,9,10)$.

Kasus 1 dan 2 merupakan pasien dengan trauma palpebra superior. Kedua kasus tersebut defek yang terjadi mengakibatkan hilangnya palpebra lebih dari $50 \%$. Ada perbedaan usia pada kasus 1 lebih muda dari pada kasus 2. Pada usia muda kelenturan kulit palpebra berbeda dengan kelenturan usia lebih tua. Kejadian trauma pada kasus 1 terjadi lebih kurang 15 tahun yang lalu, sedangkan kasus 2 baru terjadi 1 minggu yang lalu dan telah dimanipulasi tenaga medis lainnya.
Kegagalan rekonstruksi pada kasus 1 karena kelenturan kulit palpebra masih terlalu kaku dan defek terlalu luas untuk di jahit secara langsung. Pengalaman operator dalam melihat / memperkirakan tarikan yang berlebihan/kurang pada kulit palpebra sangat menentukan untuk tehnik yang akan digunakan. Bentuk defek yang berbentuk segitiga tumpul menjadi salah satu penyebab operator mengambil tehnik penjahitan langsung pada kasus 1.

Setelah 4 minggu post operasi ternyata defek masih ada, sehingga operator berencana melakukan tindakan tehnik Cutler-Beard prosedur dengan pertimbangan: 1). Kegagalan penjahitan secara langsung; 2). Usia pasien masih muda dengan kekakuan kulit masih tinggi; 3). Ukuran defek sedang-luas dapat dilakukan tehnik tersebut (6).

Kasus 2 penggunaan tehnik Cutler-Beard prosedur menggunakan flap tidak full thickness preseptal palpebra inferior. Flap yang diambil kulit dengan alasan defek palpebra superior yang terjadi karena hilangnya lapisan anterior saja. Berdasarkan flap yang diambil tersebut maka operator mengambil keputusan pemisahan flap bridge mengambil waktu 21 hari. $^{7}$ Selain itu yang menjadi pertimbangannya yang lain adanya keadaan luka dan jahitan sudah membaik.

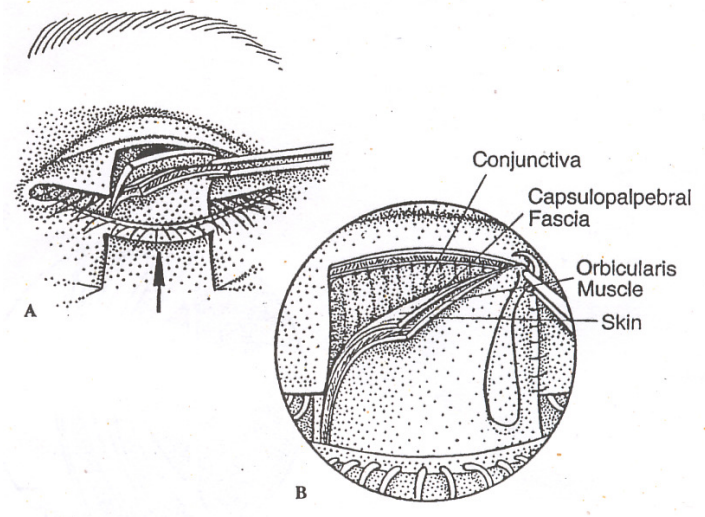

Gambar 7. Lapisan palpebra inferior yang diambil sebagai flap untuk menutup palpebra superior secara full thickness. (Diambil dari Lisman \& Yoh. Manual of Oculoplastic Surgery. 1996.223) (7).

\section{KESIMPULAN}

Telah dilaporkan 2 kasus defek palpebra superior dengan defek lebih $50 \%$. Kasus 1 gagal dilakukan rekonstruksi dengan direct closure karena hasilnya defek belum tertutup secara baik. Kasus 2 dilakukan Cutler-Beard prosedur memperoleh hasil yang baik dengan tehnik sederhana tetapi membutuhkan waktu yang lebih lama, bila dibandingkan tehnik pada kasus 1. 


\section{DAFTAR KEPUSTAKAAN}

1. Inawati. Rekonstruksi Palpebra, Dalam Naskah Lengkap. Pertemuan IImiah Regional Perdami Jawa tengah \& DIY; 2000; 16.

2. Khosh, Maurice MMD.Upper Eyelid Reconstruction. 2003. Available from: www.emedicine.com, diakses tanggal 18 November 2003.

3. Jordan DJ. Reconstruction of the Upper Eyelid. In: Ophthalmic Plastic \& Reconstrustive Surgery. Philadelphia: WB Sauders Comp.1997; 1: 356-386.

4. Bashour Mounir, MD, CM, FRCSC, FACS. Eyelid Reconstruction. Upper Eyelid; 2005. Available from: www.emedicine.com. Diakses tanggal 17 Januari 2005.

5. American Academy of Ophthalmology. Orbit, Eyelid, and Lacrimal System. 2003-2004; 7: 184-188.

6. McCord CD, Jr. System of Repair of Full Thickness Eyelid Defects, In: Oculoplastic Surgery. New York: Editor by Clinton D, McCord, Jr. Raven Press; 1982: 211-221.

7. Lisman RD and Koh JY. Composite Advancement Flap (Cutler-Beard Procedur). In: Levine. MR, MD. Manual of Oculoplastic Surgery. Second Edition. Boston: Butterworth-Heinenman; 1996; 2: 221-228.

8. Charonis GC MD. Eyelid Reconstruction. In: Ophthalmic Surgery Principles and Practice. Third Ed. George L.Spaeth. Philadelphia: WB Sauders Comp; 2003; 3: 447-458.

9. Spaeth GL. Opthalimic Surgery Principles and Practice. Philadelpia: WB Sauders; 1982; 619-620.

10. Mustarde JC. Reconstrustion of the upper lid. Edition 3th. London: Edinburgh; 199; 202-206. 